\title{
Using Standardized Examinations to Assess Engineering Programs
}

\author{
Keith A. Schimmel, Franklin G. King, Shamsuddin Ilias, \\ North Carolina A\&T State University
}

\begin{abstract}
The ABET EC2000 criteria require programs to have quality improvement processes in place to make decisions based on assessment data from student performance and program constituencies. Within this context, there is a need for development of additional quantitative measures that will be consistent over time and between instructors of whether students have mastered course learning objectives. This paper will discuss characteristics of valid quantitative assessment instruments for course learning objectives through a look at the development of the ABET EC2000 process in the chemical engineering program at North Carolina A\&T State University.

The chemical engineering program at A\&T has been experimenting with department developed standardized exam questions. This has lead to the development of a database of questions for core courses that are organized by course learning objective, degree of difficulty of question, and type of question (conceptual or analytical). The questions are delivered to students through a web-based homework system, WebAssign ${ }^{\circledR}$. A comparison will be made between nationally normed tests, i.e., the FE exam, and department developed standardized exams. Student and faculty response to development and use of standardized tests will be discussed.
\end{abstract}

\section{Introduction}

A variety of exams have been used to provide quantitative, summative assessment data for ABET EC2000 department level outcomes assessment processes. ${ }^{1,9}$ The use of the Fundamentals of Engineering exam that is developed and administered by the National Council of Examiners for Engineering and Surveying (NCEES) ${ }^{2,4,5,7,14-16}$ as well as Core Competency exams developed and administered by individual departments or colleges ${ }^{11,13}$ have been reported. These exams contain primarily multiple-choice, analytical questions with just a few conceptual questions. Online delivery and grading of the exams is available from some commercial vendors. Recently, there has been an effort to develop concept inventory questions for engineering core topics, including most of the core chemical engineering topics. ${ }^{6}$ These questions seek to measure a student's understanding of physical concepts instead of analytical ability. These questions are just now becoming available for beta testing.

This paper reports on the start of an effort to compile a combination of analytical and conceptual multiple-choice questions into a database organized by course learning objective for core chemical engineering courses at North Carolina A\&T State University. These questions may be delivered to students online via the WebAssign ${ }^{\circledR}$ homework system and automatically graded. The validity of individual questions can be determined through statistical analysis of student performance. The intent of putting together this assessment tool is to provide both formative and summative quantitative assessment data that is quick and easy for individual faculty members to obtain. It is hoped that once this type of assessment data is readily available for the chemical engineering faculty, they will use it to adjust their teaching to meet the demonstrated needs of the 
students in their classes and to provide informed advisement to students who may not be ready to take a course.

\section{Comparison of Nationally Developed Standardized Exams versus Department Developed Standardized Exams}

Standardized exams, either nationally developed or department developed, provide the opportunity to measure the understanding of many concepts quickly. This is their strength. It should be pointed out, however, that they are not good at measuring long-term retained skills such as creativity. Thus, a department outcome assessment program cannot be limited to just standardized exams.

Advantages of using the FE exam include its:

- inter-institutional benchmark value,

- ease of administration, and

- large sample size for statistical analysis of results.

Disadvantages of using the FE exam include its:

- long time constant for measuring response to changes (1-4 years depending in which year a student took a course),

- design of measuring minimal technical competencies based on learning objectives determined from national surveying,

- variable student motivation for taking the exam ${ }^{8}$,

- not being taken by all students in a program, and

- fixed exam date falling before some topics are covered in a course a student is currently taking.

These disadvantages of using the FE exam for assessment point to the advantages of a department developed instrument. A department core competency exam can provide both summative and formative assessment data so that it may serve longitudinal benchmark value (pre-course, mid-course, end-of-course, post-course). Questions can be developed at different levels of difficulty targeting the specific learning objectives of an instructor in a course. Since performance on the exam can be tied to a course grade, motivation is higher and more uniform with all students in a course taking the exam. The obvious disadvantage of using department developed standardized exams is the effort involved in constructing the exams. To aid with this task, as described next, the chemical engineering program at North Carolina A\&T State University has incorporated course committees into its assessment process.

\section{Outcomes Assessment Process Model at A\&T}

The engineering programs at A\&T have worked over the past couple of years to establish outcomes assessment processes to meet ABET requirements. ${ }^{3,10,12}$ Principles that guided the development and implementation of the OA processes were to

- Involve faculty at each step in the development process

- Have a non-administrative faculty champion have a key role in the development

- Make it sustainable so the plan will operate continuously and not fall apart after the ABET visit 
- Carefully control the amount of data collected

- Provide summarized results to faculty

- Empower faculty committees to oversee department courses and curriculum

- Empower faculty to make course and program improvement decisions.

After considerable discussion, the chemical engineering faculty agreed to the concept of having a course committee oversee the operation and assessment of each of their undergraduate core courses. They agreed and understood that the plan would be changed each year to eliminate items that were not effective and to add procedures to make it work better.

Course Assessment Committees: Each chemical engineering course assessment committee consists of at least three faculty members. These members include the instructor(s) that most often teaches the course and other faculty interested in the course content. Each committee has a coordinator that is knowledgeable in the subject area, but not the instructor who typically teaches the course. The coordinator is responsible for (1) scheduling a committee meeting during the first week of classes following the semester in which the course is taught, (2) making sure that course materials are available for the committee when it meets, (3) keeping the committee discussions on task, and (4) submitting the annual course report.

The purpose and philosophy of the course committees is to stimulate discussion among faculty members and to assess course materials, thereby, leading to documented improvement of course content, student learning, and coordination of content between courses. Toward this end, the responsibilities of the committees are:

1. To specify the assessment instruments for the course.

2. To specify the performance targets for assessing the outcomes for the course learning objectives.

3. To determine if the course syllabus was covered.

4. To determine if the course design content was met.

5. To evaluate the data from the assessment instruments to determine if the course outcomes have been met.

6. To specify the minimum course learning objectives. These objectives should reflect the desired design content of the course. Additional objectives may be added at the discretion of an individual faculty member teaching the course.

7. To select the course text(s) and software packages.

8. To prepare the Course Achievement Test (CAT) questions (The CAT exam is part of the final exam in chemical engineering core courses. It is prepared by the committee to aid the determination of whether the course learning objectives were met.)

9. To annually review the course and recommend changes regarding the course by completing the annual course report based of the instructor's report and assessment. This report goes to the Department Outcomes Assessment Committee.

The responsibility for the evaluation, maintenance, and improvement of courses and curriculum lies with the faculty. The processes that have been put into place detail how the faculty monitor department courses and curriculum. They also provide the timelines and information models that give the faculty the data needed to make process improvement decisions. The most important 
loops in the continuous improvement processes are the loops that evaluate student learning in courses and the overall curriculum. The flow model depicting the course improvement loop is given in Fig. 1. The responsibility for the improvement of the outcomes from courses lies with the course assessment committees.

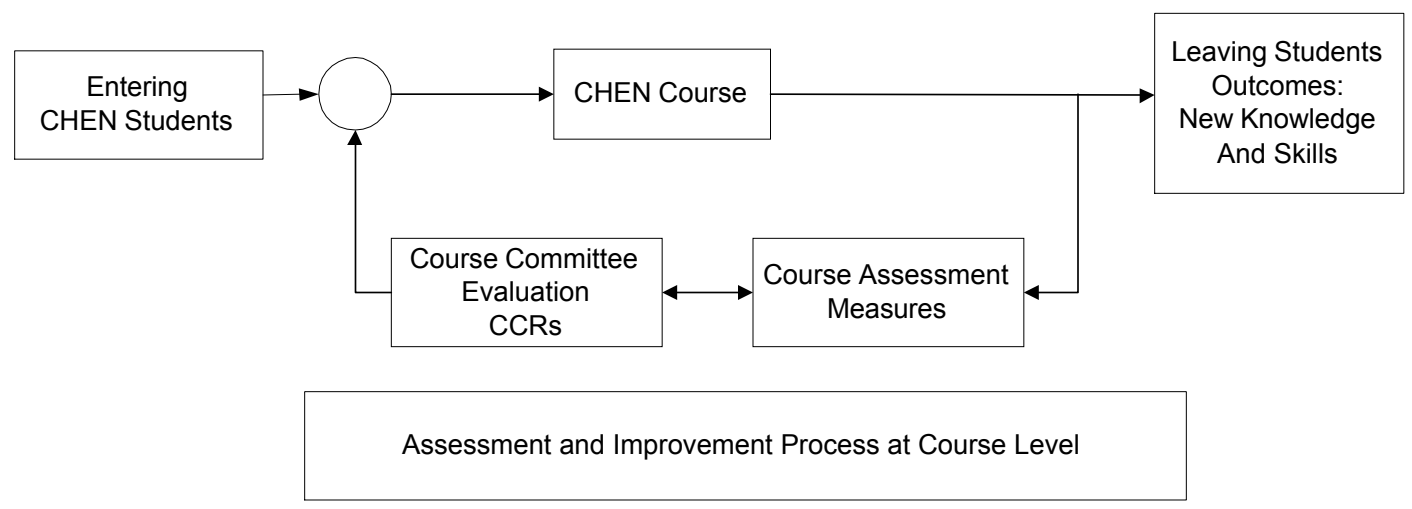

Figure 1. Course Improvement Process Model

\section{WebAssign}

After consideration of a number of software options, WebAssign was chosen as a tool to aid the development, storage, and retrieval of department developed standardized exam questions. WebAssign has been designed by science and engineering faculty as a full-feature homework system. ${ }^{17}$ It can be used in conjunction with a course management system such as Blackboard; the future plan at A\&T. It is completely web-based with a fee covering server use (located at North Carolina State University) and technical support. The WebAssign program is written in Perl, interfaces with a MySQL database, and is delivered with Apache Web Server. Individual questions are stored in the system for easy retrieval using a searchable database backend. WebAssign.net has a database of thousands of questions including those from major science and engineering publisher's textbooks. Also, colleagues from various institutions can share questions they have written and entered into the question database.

As many numbers, words, phrases, graphic files, sound files, and video files as one would like can be randomized, so that each student receives a different version of the same question. This provides an added measure of question integrity. The symbolic question type allows one to pose questions that a student answers as a formula. Any formula that is equivalent to the answer will be marked as correct. WebAssign allows for feedback for all question types based on the type of error. Essay questions currently are not automatically graded, but a Latent Semantic Analysis technique is being tested for this application. Anything that can be written in HTML can be put into a WebAssign question.

\section{Exam Database Structure}

The questions in the exam database have been placed in ten categories corresponding to the core courses in the department (see Table 1). The questions for each course are further categorized by course learning objective. Some course learning objectives that would be difficult to try to 
measure have been removed. A sample list of learning objectives is provided in Table 2 for the Sophomore level material and energy balance course.

Table 1. Core Chemical Engineering Courses in the Database

\begin{tabular}{|l|c|}
\hline \multicolumn{1}{|c|}{ Course } & Number of Learning Objectives \\
\hline CHEN 200: Chemical Process Principles & 26 \\
\hline CHEN 220: Numerical Analysis & 15 \\
\hline CHEN 300: Fluid Mechanics & 12 \\
\hline CHEN 310: Thermodynamics & 14 \\
\hline CHEN 316: Analysis of Chemical Process Data & 11 \\
\hline CHEN 320: Heat Transfer & 15 \\
\hline CHEN 340: Process Dynamics and Control & 20 \\
\hline CHEN 350: Chemical Reaction Engineering & 14 \\
\hline CHEN 400: Mass Transfer & 13 \\
\hline CHEN 430: Process Design I & 8 \\
\hline
\end{tabular}

Table 2. Typical List of Learning Objectives - CHEN 200

1. Convert a quantity expressed in one set of units into its equivalent in any other dimensionally consistent units using conversion factor tables.

2. Identify the units commonly used to express both mass and weight in SI, cgs and American Engineering System (AES) units and use Newton's second Law to convert one into the other.

3. Calculate density from specific gravity, volume from moles or mass, mole fractions from mass fractions or mass composition and the opposite conversions.

4. Convert a temperature reading in one of the four common temperature scales to any of the other scales.

5. Define pressure, atmospheric pressure, absolute pressure and gauge pressure.

6. Define enthalpy and heat capacity and determine the enthalpy of a pure substance using heat capacity.

7. List the information needed to define a process stream.

8. Given a description of a steady-state process, draw and label a flowchart, chose a basis of calculation, perform a degree-of-freedom analysis.

9. Write mass-balance equations for a single-unit, non-reactive process and solve the set of equations.

10. Write sets of mass-balance equations for a multi-unit, non-reactive process and solve the sets of equations.

11. Solve problems with gaseous components by applying the ideal gas law for pure streams and Dalton's Law for gas mixtures.

12. Given a description of a process system in which a volumetric flow rate is either specified or requested for any process stream, complete the mass balance on the system.

13. Determine the vapor pressure of pure liquids using the Antoine equation, Cox chart and other estimation methods.

14. Determine the heat of phase change for a pure chemical using tables, charts and estimation methods. 
15. Given a process in which a specified mass $m$ of a species goes from one state to another and tabulated values of $\mathrm{U}$ or $\mathrm{H}$ for the species at the initial and final states are available, calculate $\Delta \mathrm{U}$ or $\Delta \mathrm{H}$. Given values of $\mathrm{P}$ and $\mathrm{V}$ at each state, calculate $\Delta \mathrm{H}$ from the previously calculated $\Delta \mathrm{U}$ or vice versa. Carry out the corresponding calculations to determine $\Delta \mathrm{U}$ and $\Delta \mathrm{H}$ for a flowing stream.

16. Solve steady-state energy balance problems for non-reactive processes.

17. Define stoichiometry, fractional conversion, limiting and excess reactants.

18. Given the fractional conversion for a reaction, calculate the mass and molar amounts of all participating species.

19. Write and solve the mass -balance equations on processes that include a chemical reactor with a single reaction.

20. Write and solve the mass -balance equations on processes that include a chemical reactor with multiple reactions or an equilibrium reaction.

21. Determine heat of reaction using Hess's law and standard heats of formation and standard heats of combustion.

22. Solve steady-state energy balance problems on reactive processes.

23. Apply the lever rule (and the inverse lever rule) the material balances on two-phase systems when phase diagrams are given (e.g. solid-liquid phase diagram, enthalpycomposition diagram).

24. Use the psychometric chart to obtain data to carry out material and energy balance calculations on a heating, cooling, humidification or dehumidification process involving air and water at $1 \mathrm{~atm}$.

25. Determine the flow rate and composition of the two streams leaving a process unit in equilibrium for the following cases: vapor-liquid equilibrium, solid-liquid equilibrium and the saturation of a volatile component in a non-condensable gas.

26. Solve problems with gaseous components by applying the ideal gas law or the compressibility factor equation of state for pure streams and Dalton's Law or Kay's rule for gas mixtures.

Within each learning objective, questions are further categorized according to difficulty (advanced or basic question) and type (primarily conceptual or analytical). Analytical questions have been set up so that parameter values are randomly chosen from a specified range of values each time the question is asked.

\section{Results}

The Spring 2003 semester is the first semester in which WebAssign delivery of department standardized exams will be available. Therefore, the merit of this approach is yet to be fully understood. However, some observations from the process to this point can be made.

Past efforts to use the FE exam as an assessment tool for the A\&T chemical engineering program have met with limited success. Few students take the exam, and there is variable motivation for those who do take it. Therefore, there has been a compelling need to develop the standardized exams at the department level. 
The results of the use of the course committee structure to aid the development of the standardized exams have been mixed. Faculty members have not wanted to devote much time to developing and critiquing questions as part of the committee activities. However, the requirement of including standardized exam questions on core course finals along with the overall assessment process have served to provide a good vehicle to develop a database of questions with solutions matched to course learning objectives. This has provided the necessary starting point for department administrators to use department resources to automate the delivery and scoring of the questions.

While there are a number of commercially available course management and homework system options available, WebAssign is uniquely suited to the needs of the departmentally developed standardized exams. It is based around exam questions that may be easily retrieved if properly named, rather than courses or full exams. Interfacing it with the North Carolina State mandated course management system, Blackboard, is currently undergoing testing. It has been developed specifically for those who want to deliver science and engineering questions to students without students being able to copy the answers from other students. WebAssign has been willing to work out pricing structures that take into account its use for short periods of time in a given course to do pre-course and post-course testing. Questions may be coded either after training our own personnel or by paying WebAssign staff. Additionally, the opportunity exists to use questions from textbooks as well as other WebAssign faculty users.

\section{Conclusions}

Now that this assessment tool has been developed, future uses such as analysis of transfer of knowledge between courses, faculty development, and evaluation of the effectiveness of classroom innovations are planned.

\section{Acknowledgement}

This material is based upon work supported by the National Science Foundation under Grant No. EEC-0230645.

\section{Bibliography}

1) Ewell, P. T. (1998), 'National Trends in Assessing Student Learning," Journal of Engineering Education, 87(2), 107-113.

2) Gerstner, L.V., Jr. (2001), "High Marks for Standardized Tests,” Prism, February, 64.

3) King, F.G., Schimmel, K.A. (2001), "Using Course Committees to Engage Faculty in the Assessment of Student Outcomes," Proceedings of Best Assessment Processes in Engineering Education IV: A Working Symposium, Rose-Hulman Institute of Technology, Terre Haute, IN.

4) Koehn, E. (1989), "Fundamentals of Engineering Exam: Motivation and Review Enhances Pass Rate," Journal of Professional Issues in Engineering Education and Practice, 115(3), 289-296.

5) Mazurek, D.F. (1995), "Consideration of FE Exam for Program Assessment," Journal of Professional Issues in Engineering Education and Practice, 121(4), 247-249.

6) Miller, R.L., Streveler, R.A., Olds, B.M. (2002), "How Chemical Engineering Seniors Think about Mechanisms of Momentum Transport," Proceedings of the 2002 ASEE Annual Conference \& Exposition, Montreal, Canada.

7) Nirmalakhandan, N., White, K. (2000), "Course Refinement through Outcome Assessment: A Case Study," Journal of Professional Issues in Engineering Education and Practice, 126(1), 27-31.

8) Rodriguez, H.V. (1989), "How Many Engineering Colleges Require Students to Take the FE Exam," Engineering Education, 79(3), 437-438. 
9) Rogers, G. M. (2000), “EC2000 and Measurement: How Much Precision is Enough?” Journal of Engineering Education, 89(4), 161-165.

10) Sarin, S., Schimmel, K., Stanfield, P., King, F., Park, E. (2002), "Empowerment of Course Committees in Engineering Education," Proceedings of International Conference on Engineering Education-2002, UMIST, Manchester, UK.

11) Schimmel, K.A., King, F.G. (2001), "Using Department Developed Standardized Examinations to Assess Academic Programs," Proceedings of Best Assessment Processes in Engineering Education VI: A Working Symposium, Rose-Hulman Institute of Technology, Terre Haute, IN.

12) Schimmel, K.A., King, F.G. (2001), "A Model for Faculty Involvement in Closing the Outcomes Assessment Loop," 2001 Proceedings of the 2001 ASEE Annual Conference \& Exposition, Albuquerque, NM.

13) Terry, R.E., Wilding, W.V., Harb, J.N. (2002), "A Senior Exam to Assess the Learning of Core Competencies in a Chemical Engineering Curriculum," Proceedings of the 2002 ASEE Annual Conference \& Exposition, Montreal, Canada.

14) Watson, J.L. (1998), "An Analysis of the Value of the FE Examination for the Assessment of Student Learning in Engineering and Science Topics," Journal of Engineering Education, 87(3), 305-311.

15) White, K., LeFevre, W., Steadman, J., Smith, J. (2000), "Using the Fundamentals of Engineering (FE) Examination to Assess Academic Programs," Proceedings of Best Assessment Processes in Engineering Education III: A Working Symposium, Rose-Hulman Institute of Technology, Terre Haute, IN.

16) Wicker, R.B., Quintana, R., Tarquin, A. (1999), "Evaluation Model Using Fundamentals of Engineering Examination, Journal of Professional Issues in Engineering Education and Practice, 125(2), 47-55.

17) Risley, J.S. (2002), Webassign User's Manual 3.5, North Carolina State University, Raleigh, NC. (www.webassign.net)

\section{KEITH SCHIMMEL}

Keith A. Schimmel is Associate Professor and Director of the chemical engineering program at North Carolina A\&T State University and a registered professional engineer in North Carolina. He received a BS degree in chemical engineering from Purdue University. He also holds MS and $\mathrm{PhD}$ degrees in chemical engineering from Northwestern University.

\section{FRANKLIN KING}

Franklin G. King is Professor of chemical engineering at North Carolina A\&T State University. Dr. King received his BS, MS and D.Sc. degrees in chemical engineering from Penn State, Kansas State and Stevens Institute, respectively. He also holds a M.Ed. degree from Howard University.

\section{SHAMSUDDIN ILIAS}

Shamsuddin Ilias is Professor of chemical engineering at North Carolina A\&T State University and a registered professional engineer in Ohio. Dr. Ilias received his BS, MS and Ph.D. degrees in chemical engineering from Bangladesh University of Engineering \& Technology (Dhaka), University of Petroleum \& Minerals (Dhahran), and Queen's University at Kingston (Canada), respectively. 